\title{
MINIMUM NUMBER OF TRANSFER UNITS AND REBOILER DUTY FOR MULTICOMPONENT DISTILLATION COLUMNS
}

\author{
Valentin Pleşu ${ }^{\mathrm{a}}$, Alexandra Elena Bonet Ruiz ${ }^{\mathrm{a}^{*}}$, Jordi Bonet $^{\mathrm{b}}$, Joan Llorens $^{\mathrm{b}}$, \\ Petrica Iancu ${ }^{\mathrm{a}}$ \\ ${ }^{a}$ University POLITEHNICA of Bucharest, Centre for Technology Transfer in Process \\ Industries (CTTPI), 1, Gh. Polizu Street, Bldg A, Room A056, RO-011061 Bucharest, \\ Romania \\ ${ }^{b}$ University of Barcelona, Department of Chemical Engineering, 1, MartíiFranquès \\ Street, $6^{\text {th }}$ Floor, E-08028 Barcelona, Spain
}

\section{Abstract}

3 Some guidelines to evaluate distillation columns, considering only basic thermodynamic data and principles, are provided in this paper. The method allows a first insight to the problem by simple calculations, without requiring column variables to ensure rational use of energy and low environmental impact. The separation system is approached by two complementary ways: minimum and infinite reflux flow rate. The minimum reflux provides the minimum energy requirements, and the infinite reflux provides the feasibility conditions. The difficulty of separation can be expressed in terms of number of transfer units (NTU). The applicability of the method is not mathematically limited by the number of components in the mixture. Several mixtures are rigorously simulated as illustrative examples, to verify the applicability of the approach. The separation of the mixtures, performed by distillation columns, is feasible if a minimum NTU can be calculated between the distillate and bottom compositions.

5 Once verified the feasibility of the separation, the maximum thermal efficiency depends 
1 only on boiling point of bottom and distillate streams. The minimum energy

2 requirements corresponding to the reboiler can be calculated from the maximum

3 thermal efficiency, and the variation of entropy and enthalpy of mixing the distillate and

4 bottom streams.

5

6 Keywords: distillation column, thermal efficiency, minimum number of transfer units,

7 residue curve map, feasibility, minimum reboiler duty, infinite/infinite analysis.

8

9 *Corresponding author .Tel.: +4021-4023916; fax: +4021-3185900

10 E-mail address: a_bonet@chim.upb.ro

11

12 Nomenclature

$13 D$ distillate flowrate $(\mathrm{kmol} / \mathrm{h})$

$14 L \quad$ reflux flowrate $(\mathrm{kmol} / \mathrm{h})$

$15 \mathrm{M} \quad$ number of chemical reactions

16 NC number of components in the system

$17 Q \quad$ overall thermodynamically calculated distillation column duty $(\mathrm{kW})$

$18 Q^{\prime} \quad$ distillation column duty required for mixture separation $(\mathrm{kW})$

19 Q” enthalpy of vaporization flow for the distillate stream $(\mathrm{kW})$

$20 \mathrm{Q}_{\mathrm{min}} \quad$ minimum distillation column duty, estimated by simulation $(\mathrm{kW})$

$21 \mathrm{R} \quad$ ideal gas constant, $8.314 \mathrm{~kJ} /(\mathrm{kmol} \cdot \mathrm{K})$

$22 \mathrm{r} \quad$ reflux ratio $(\mathrm{kmol} / \mathrm{kmol}$ distillate $)$

$23 r_{j} \quad$ reaction rate of the reaction $\mathrm{j}(\mathrm{kmol} /(\mathrm{kmol} \cdot \mathrm{h})$

$24 \mathrm{r}_{\min } \quad$ minimum reflux ratio $(\mathrm{kmol} / \mathrm{kmol}$ distillate $)$

$25 \mathrm{~S} \quad$ entropy $(\mathrm{kJ} /(\mathrm{kmol} \cdot \mathrm{K}))$ 


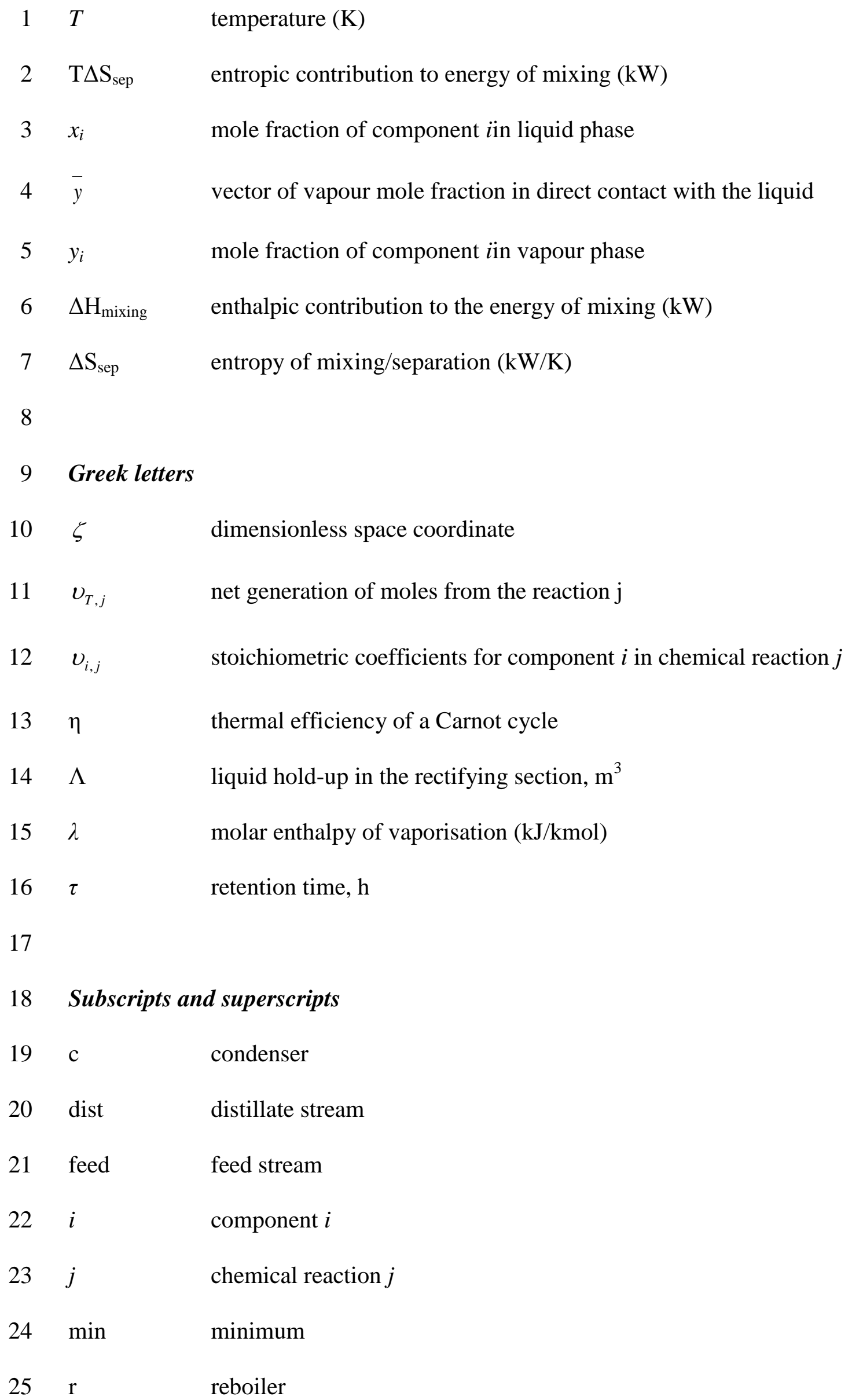


1 residue residue stream

2

3 Abbreviations

4 IA isoamylenes (2-methyl-1-butene + 2-methyl-2-butene)

$5 \mathrm{MeOH} \quad$ methanol

6 MESH Mass Equilibrium Summation Enthalpy model

$7 \quad$ NTU number of transfer units

8 TAME tert-amyl-methyl- ether

10 1. Introduction

11 At early stages of process strategy for a new design, i.e. conceptual design step, it is

12 important to gather the required information to decide when it is worth to proceed to

13 further detailed studies, avoiding the possibility to obtain novel design with low

14 improvement potential. This first decision should be taken based on thermodynamic

15 data, before details about the process are available. This lack of data is compensated by

16 the fact that in early design stages, process operating parameters exact values are not

17 expected. Therefore, instead of fixing an arbitrary reflux to the column, it would be

18 preferable to fix it to infinite, or to its minimum value. Although it is not industrially

19 realistic, these assumptions provide the potential for the proposed process, and the

20 alternative processes to be compared easily, based on fast calculations.

21 One of the methods simplifying the distillation column model is the infinite/infinite

22 analysis. The Mass Equilibrium Summation Enthalpy (MESH) rigorous model used by

23 most of commercial process simulators usually has five degrees of freedom which

24 basically are covered by the following parameters: distillate flow rate, reflux ratio,

25 number of stages, feed stage and pressure, at a specified feed stream. Assuming an 
1 infinite reflux flow rate, then the feed stream has no influence on the set of feasible

2 column profiles, only the pressure influences them. Once fixed the feed stream and the

3 distillate flow rate, the compositions of bottom and distillate streams are defined by

4 mass balance, that fulfils the condition of feasibility (existence of a column profile

5 between the distillate and bottoms compositions) and that the column profile contains a

6 singular point (pure component or azeotrope) according to the infinite/infinite

7 hypothesis [1]. The infinite/infinite analysis can provide easily interesting insights of

8 complicated processes that would be difficult to obtain by rigorous simulations, e.g. [2].

9 The uncertainty between unfeasibility and mathematical convergence difficulties is

10 avoided. This analysis has been recently extended to study kinetically controlled

11 reactive distillation columns by Plesu et al [3], where the importance of energy savings

12 is underlined for any small improvement of the distillation process. The above

13 mentioned advantages of the infinite/infinite analysis allow tobe used and computer

14 implemented by important chemical companies [4].

15 However, the assumption that some parameters are infinite, does not imply that all the

16 others must be also infinite, all the intensive variables, such as concentrations, degrees

17 of recovery, and temperatures, remain finite. In the same time, an infinite reflux flow

18 rate inside the distillation column, does not exclude finite input and output flow rates.

19 No output streams are obtained at total reflux $(D=0)$, however these can be considered,

20 when the reflux flow rate is infinite $(\mathrm{L} \rightarrow$ infinite). Similarly, an infinite reflux ratio can

21 be obtained when $\mathrm{L} \rightarrow$ infinite, or $\mathrm{D}$ is zero $(\mathrm{r}=\mathrm{L} / \mathrm{D})$, and the infinite/infinite analysis

22 assumes L infinite. At infinite reflux, a certain separation in two output compositions is

23 achieved by a minimum number of transfer units, who in turn can be infinite. The

24 infinite number of transfer units is generated by the presence of a singular point, and

25 their location is around this point, and not all along the column height. 
1 Usually, the feasibility of a certain separation is checked by the so called residue curve

2 maps, which are assumed to represent graphically a set of composition column profiles

3 of a packed column, operated at infinite reflux flow rate [5]. The determination of the

4 number of transfer units (NTU) for these profiles provides a quantification of the

5 difficulty of the separation, which is not provided directly by the residue curves alone

$6[6,7]$. The agreement between residue curves and packed column profiles at infinite

7 reflux has been corroborated by some authors $[8,9]$ butfor reactive distillation it is not

8 always true [10].

9 On the other hand, nowadays, the main drawback at the initial stage of process design is

10 the lack of a commonly used, non-iterative and fast method to estimate the energy

11 requirements of a distillation column [11], and usually these are determined later by

12 rigorous simulation (MESH model) [12]. A simultaneous approach is required to link

13 the models of the distillation columns with those of process heat exchange network

14 [13]. Estimation of distillation columns minimum energy requirements would be very

15 useful, as input for pinch analysis, which could provide an early value for the minimum

16 energy requirement of the global process. The environmental and economic aspects can

17 be assessed only after the energy requirements are determined. Energy efficiency

18 improvement for existing processes contributes to $\mathrm{CO}_{2}$ emissions reduction [14].

19 Resource (energy) efficiency is a very important future trend in Process Systems

20 Engineering [15]. An exact cost value is very difficult to calculate, but a value

21 proportional to the cost can be provided for a distillation column, based on the

22 minimum number of transfer units $\left(\mathrm{NUT}_{\min }\right)$ required and the minimum reboiler duty

$23[16]$.

24 Hence, this paper focuses on the determination of minimum heat duty requirements of

25 an adiabatic distillation column, considering only thermodynamic data and principles, 
1 as a basic method towards understanding and application to some more special schemes,

2 such as vapour recompression (e.g. [17], [18]), heterogeneous azeotropic distillation

3 [19], diabatic columns, divided wall column. Therefore, a divided wall column can be

4 modelled as combination of adiabatic distillation columns [20] or as a column globally

5 adiabatic [21] because the heat exchange takes place just internally. The lower energy

6 consumption of the divided wall columns can be related to higher second law efficiency

$7 \quad[22]$.

10 2. Method development

\subsection{Brief state of the art of methods to calculate distillation column parameters}

14 The available methods to calculate distillation columns parameters are classified in 15 three main groups [24]: rigorous simulation models, stage by stage calculations and 16 analysis fixing parameters at limit conditions. The rigorous simulation models require

17 have as input data the reflux, number of stages (discrete variable) and feed plate among

18 the variables provided, e.g. MESH model [25] and the product purities are output data.

19 The resolution of these models requires a high computation effort as the model is made

20 of a large number of equations that are solved together until convergence is achieved.

21 Moreover, it is the key product purity that is usually known and not the column

22 parameters required by the model.

23 The second group, the stage by stage calculation models, deals with the sequential

24 resolution of the model as a consequence of using a product composition as input

25 parameter. This simpler resolution of the model is based on the fact that the data flow 
1 can be inverted as long as the number of degrees of freedom of the distillation unit is the

2 same (Figure $\gg \gg \gg>$ ). The key-component composition in an output stream calculated

3 from the rigorous models is used now as input stream while the number of stages

4 becomes a calculated output. For binary mixtures, McCabe-Thiele method assumes

5 mass balances and constant molar overflow while Ponchon Savarit method takes into

6 account the energy balances e.g. [26]. The input data are the product key component

7 purity and an optimal feed plate condition that minimizes the required number of stages,

8 while the number of stages and optimal feed plate becomes output data. The reflux is

9 usually fixed according to a rule of thumb that calculates its optimum value starting

10 from its minimum value (in the interval of 1.2 to 1.5 times the minimum). The stage by

11 stage method can be extended to ternary mixtures, but in this case two degrees of

12 freedom are required to define the output stream, e.g. Boundary Value Method [27]

13 [28]. A further increase in the number of components cannot be easily handled due to

14 the limitation of the five degrees of freedom available in the distillation column. Three

15 degrees of freedom are fulfilled when specifying the pressure (affects thermodynamics),

16 reflux (direct influence on operation costs) and number of stages (direct influence on

17 capital costs), i.e. the reflux and number of stages are required to optimize the column.

18 These drawbacks appearing for multicomponent mixtures can be solved searching the

19 distillate composition that requires the shortest line from distillate to bottoms

20 composition becoming an optimization problem [29] [30]. This criteria of the shortest

21 line is an approximation of the lower number of stages criteria used by McCabe Thiele.

22 The above mentioned methods can be used to calculate the minimum reflux by

23 decreasing the reflux value until the number of stages becomes infinite. However, the

24 methods are simplifying from the beginning the model, assuming infinite number of

25 stages and require less computational effort to calculate the minimum reflux. 
1 The third group of methods simplifies the model by fixing the number of transfer units

2 and/or reflux at boundary conditions, i.e. minimum or infinite values. Infinite reflux

3 means that for non-reactive packed column, its column composition profile matches a

4 section of a residue curve. Infinite NTUs means that the column composition profile

5 will reach a pinch point (non-evolution of the concentration). Infinite NTUs and infinite

6 reflux means that the pinch points reached are singular points. The Static Analysis [32]

7 assumes infinite reflux flow rate and minimum NTU. The Static Analysis is used to

8 provide a feasible value for distillate and bottoms streams compositions to be used in

9 the stage by stage calculation models, whose results are then employed as initialization

10 values of rigorous models [24]. The assumption of finite reflux and infinite NTU is used

11 by the pinch-based methods to calculate the minimum reflux under the Zero Volume

12 Criterion [32], Minimum Angle Criterion [33] or Eigenvalue Criterion [34]. All these

13 criteria suffer the drawback that the selection of the relevant pinch points can be rather

14 complicated, particularly for mixtures with more than three components. The

15 Rectification Body Method [34] [35] calculates all the pinch points for the rectifying

16 and stripping sections and defines a polyhedron body for each section where the pinches

17 are the vertex. The minimum reflux corresponds to the point where both bodies intersect

18 each other. When a column profile composition is known, this point can be used as

19 initial value for a stage by stage calculation model. This occurs in a distillation column

20 operated at minimum reflux characterized by a feed pinch. The feed pinch composition

21 can be calculated by the Rectification Body Method and then Feed Pinch Method [37] is

22 applied to perform the stage by stage calculation from feed pinch composition to both

23 column ends. The idea of using infinite NTU to calculate the minimum reflux was also

24 developed in the USSR literature [38]. The Feed Angle Method [39] is combining

25 elements of the above mentioned methods and an additional vertex is added to the 
1 linearized rectification bodies to take into account the curvature providing very accurate

2 results for the minimum energy demand or reflux. Therefore, the nowadays available

3 methods to determine the minimum energy demand are based on a trial and error

4 method to find the minimum reflux that assures a feasible column profile from distillate

5 to bottoms composition under the infinite number of stages or transfer units assumption.

6 In a similar way as the infinite number of stages assumption at finite reflux, the

7 assumption of infinite reflux flow rate and infinite number of transfer units was

8 developed in USSR in 1971 [1], rediscovered in 1993 [40] achieving nowadays a high

9 grade of maturity [3].

10 A new method in mid-way of the rigorous and shortcut models has recently been

11 proposed [31]. The mass/energy balance calculation for an overall distillation column as

12 well as certain key stages are incorporated into the short-cut model and solved

13 iteratively. It has solved successfully complex distillation systems.

14 In the present manuscript, an original non iterative method based on thermodynamic

15 efficiency is proposed. Composition profiles are determined for reactive packed

16 distillation columns operated at infinite reflux. The calculation of the minimum reflux

17 or energy demand of a distillation column is performed based on thermodynamic

18 efficiency, assuming a thermodynamic cycle. The number of stages and the reflux are

19 related by their minimum values [41] and therefore provides a base for more rigorous

20 computations. The aim of the proposed methodology is to provide additional fast and

21 easy to use tools for the conceptual design and not to substitute any of the existing

22 methods. It is recommended to explore an initial great number of alternatives, proceed

23 then with methods of increasing accuracy and then apply rigorous enough simulation

24 models. On the way, the alternatives with lower performance are disregarded and in the

25 end, the few most promising alternatives are subjected to a detailed evaluation. The 
1 simplest existing methods to calculate the minimum number of stages and reflux are

2 useful for ideal mixtures, e.g. [42] [43], and the proposed method is able to solve any

3 multicomponent distillation process in a simplified way.

4

$5 \quad 2.2$ A method to estimate the minimum Number of Transfer Units (NTU)

6

$7 \quad$ Very often packed columns are modelled considering the concept of Number of

8 Transfer Units (NTU), according to a dimensionless expression [23]. The NTU

9 necessary for a given separation depends only on the composition column profile, and it

10 does not depend on the characteristics and performance of the packing. The NTU was

11 defined by [44] as:

$12 N T U_{T}=\int_{y 1}^{y 2} \frac{d \overline{y_{i}}}{\Delta y}=\int_{y 1}^{y 2} \frac{d \overline{y_{i}}}{\left(\overline{y_{i}}-y_{i}\right)}$

13 where $y$ is the vapour concentration in equilibrium with the liquid, and $\bar{y}$ is the vapour

14 concentration in direct contact with the liquid. The difference $\bar{y}_{i}-y_{i}$ is the driving force

15 for the component $\mathrm{i}$ transfer from the liquid phase to the vapour phase. This expression

16 is used when the total number of transfer units along the overall height of the column is

17 fixed. Applying differentiation, it becomes:

$18 \quad d N T U=\frac{d \overline{y_{i}}}{\left(\overline{y_{i}}-y_{i}\right)}$

19 In this way, the dependence of the composition versus NTU is:

$20 \quad \frac{d \overline{y_{i}}}{d N T U}=\overline{y_{i}}-y_{i}$

21 For a non-reactive distillation column, the mass balance on the rectifying section is: 


$$
1 \quad V \cdot \overline{y_{i}}=L \cdot x_{i}+D \cdot x_{i}^{D}
$$

2 Where, $\mathrm{V}$ is the vapour molar flow rate, $\mathrm{L}$ is the liquid molar flow rate, and $\mathrm{D}$ is the

3 distillate flow rate. Assuming infinite reflux flow rate then L and V are infinite, whereas

$4 \mathrm{D}$ is a finite number and applying the l'Hôpital rule,

$$
5 \quad \overline{y_{i}}=x_{i}
$$

6 and, the NTU expression becomes, in the case of infinite reflux, the following equation:

$$
7 \quad \frac{d x_{i}}{d N T U}=x_{i}-y_{i}
$$

8 The similitude of this equation with the residue curve expression, without chemical

9 reaction, is obvious. The dimensionless time of the residue curve can be directly related 10 to the number of transfer units (NTU).

$11 d \xi=d N T U$

12 The coincidence of the residue curve profile with the profile of a packed column

13 operating at infinite reflux, makes the residue curves useful to check the feasibility of

14 distillation systems, without chemical reaction. In this paper, the dimensionless time of

15 the residue curves has been equalised to NTU. This is one of the main contributions of

16 the present paper, as this fact has important implications. The agreement between

17 residue curves and packed column profiles at infinite reflux for non-reactive systems

18 has been corroborated by some authors $[8,9]$ but it was not previously identified in

19 literature that the dimensionless time of the residue curves matches the minimum NTU.

20 The residue curve maps are just used to check the feasibility of separation systems, but

21 as it is related to the NTU, it means that it is also possible to quantify how difficult is

22 the separation. 


$$
1 \quad \frac{d N T U}{d x_{i}}=\frac{1}{x_{i}-y_{i}}
$$

2 The value of NTU necessary to change the concentration of a component between $x_{i}^{0}$

3 and $\mathrm{x}_{\mathrm{i}}$ is:

5

$$
N T U=\int_{x i, 0}^{x i} \frac{d x_{i}}{x_{i}-y_{i}}
$$

6 A similar equation for NTU dependence of composition can be also determined for

7 reactive systems. The molar balance for the rectifying section of a reactive distillation 8 column is:

$9 \quad V \cdot \overline{y_{i}}=D \cdot x_{i}^{D}+L \cdot x_{i}+\Lambda \cdot \sum_{j=1}^{M} v_{i, j} \cdot r_{j}$

10 where, $\Lambda$ is the liquid hold-up in the rectifying section and $r_{j}$ is the reaction rate in

11 rectifying section. The overall molar balance is:

$12 \quad V=D+L+\Lambda \cdot \sum_{j=1}^{M} v_{T, j} \cdot r_{j}$ where $v_{T, j}=\sum_{i=1}^{N} v_{i, j}$

13 From the last two equations:

$14 \quad\left(D+L+\Lambda \cdot \sum_{j=1}^{M} v_{T, j} \cdot r_{j}\right) \cdot \overline{y_{i}}=D \cdot x_{i}^{D}+L \cdot x_{i}+\Lambda \cdot \sum_{j=1}^{M} v_{i, j} \cdot r_{j}$

15 From these equations, one obtains:

$16 \overline{y_{i}}=\frac{\frac{D}{L} \cdot x_{i}^{D}+x_{i}+\frac{\Lambda}{L} \cdot \sum_{j=1}^{M} v_{i, j} \cdot r_{j}}{\frac{D}{L}+1+\frac{\Lambda}{L} \cdot \sum_{j=1}^{M} v_{T, j} \cdot r_{j}}$

17 As $\mathrm{L}$ is infinite and $\mathrm{D}$ is a finite number, then $\mathrm{D} / \mathrm{L} \rightarrow 0$ and $\Lambda / \mathrm{L}$ corresponds to the

18 residence time $(\tau)$ on the column section: 


$$
1 \overline{y_{i}}=\frac{x_{i}+\tau \cdot \sum_{j=1}^{M} v_{i, j} \cdot r_{j}}{1+\tau \cdot \sum_{j=1}^{M} v_{T, j} \cdot r_{j}}
$$

2 Notice that the overall molar balance in the rectifying section becomes independent of

3 distillate composition withdrawal. Assuming that the distillate composition is close to $\mathrm{x}_{\mathrm{i}}$

4 composition, then $r_{j}$ can be calculated for composition $x_{i}$. Otherwise, an average reaction

5 rate for the overall section should be considered, and the method could lose its simple

6 form. The retention time is linked to the height of the column for which $r_{j}$ is calculated.

7 Therefore, assuming an average reaction rate, the retention time is changing along the

8 column profile, depending on initialization point.

$9 \quad \frac{d \overline{y_{i}}}{d N T U}=\frac{d \overline{y_{i}}}{d x_{i}} \cdot \frac{d x_{i}}{d N T U}$

10 From Eqs.(3) and (14) results in:

$11 \frac{d x_{i}}{d N T U}=\left(y_{i}-\frac{x_{i}+\tau \cdot \sum_{j=1}^{M} v_{i, j} \cdot r_{j}}{1+\tau \cdot \sum_{j=1}^{M} v_{T, j} \cdot r_{j}}\right) \cdot\left(\frac{d \overline{y_{i}}}{d x_{i}}\right)^{-1}$

12 For the case of simple distillation and for first order reactions, without variation of

13 number of moles, $\frac{d \overline{y_{i}}}{d x_{i}}=c t=1$ the Eq. (16) can be written as:

$14 \frac{d x_{i}}{d N T U}=y_{i}-x_{i}$ 
1 For systems of reactive distillation, the expression $\frac{d \overline{y_{i}}}{d x_{i}} \neq c t$ and is more complex. The

2 present study is focused on the simplified case when $\frac{d \overline{y_{i}}}{d x_{i}}=c t=1$. In this case, Eq. (16)

3 becomes:

$$
4 \frac{d x_{i}}{d N T U}=y_{i}-\frac{x_{i}+\tau \cdot \sum_{j=1}^{M} v_{i, j} \cdot r_{j}}{1+\tau \cdot \sum_{j=1}^{M} v_{T, j} \cdot r_{j}}
$$

5

6 Therefore, in this paper, some new points of view related to residue curve maps are

7 introduced, such as the use of integration results in a NTU map, in addition to the

8 differential results in a residue curve map. This provides additional information about

9 the difficulty of the separation.

10

$11 \quad 2.3$ A method to determine the minimum reboiler duty and reflux

13 For a distillation column, a first approach to determine the minimum energy

14 consumption is assuming it proportional to the distillate flow rate [45], without taking

15 into account the reflux. This is in agreement with heuristic, that a direct separation

16 sequence is preferable to other topologies.

17 The product recovered by the bottom stream of the distillation column has been heated,

18 but the entire product collected by the distillate stream has been previously evaporated,

19 consuming more energy. The extractive agents used to enhance some distillation

20 processes usually have high flowrates, their boiling point is relatively high and they are

21 not evaporated, being recovered by the bottom stream. The refluxed flowrate which 
1 represents a material stream making a closed cycle inside the column is not taken into

2 account (Figure 1).

3 The heat distribution taking place in the distillation column is schematically represented

4 in Figure 1. On one side there is the closed thermodynamic cycle in which the

5 separation takes place (black area). On the other side there is the energy required to

6 collect the distillate flowrate at the top of the column (grey area). According to this

7 distribution, the overall reboiler duty is calculated as a sum between the energy required

8 to perform the separation and the energy required to produce the distillate stream. The

9 thermodynamic cycle as represented is a simplification which allows us to estimate the

10 energy consumption induced by the reflux rate. In a real distillation column, there is the

11 mixing between liquid and vapour streams. The mixing between the descending liquid

12 and the ascending vapour generates irreversibility, which cannot be avoided, no matter

13 the number of stages or transfer units employed. Although the distillation column can

14 be considered having a great number of stages or transfer units, the change of

15 composition takes places only in a few stages and most of the column profile presents

16 wide sections where the compositions do not change. In order to avoid column profiles

17 calculations, as a first approximation, a reversible cycle can be assumed with no internal

18 mixing, where the feed stream does not produce a change of entropy in the feed plate.

19 The ideal (Carnot) efficiency is widely used for heat engines, e.g. [46], but it has never

20 been applied before to a distillation column, even though Carnot [47] already claimed

21 that any system consuming heat at a certain temperature and delivering it at a lower

22 temperature can be studied as a thermal cycle. In literature, the thermodynamic aspects

23 of distillation columns are studied from exergy point of view, e.g. [48], which provides

24 a performance value thatcannot be related to the reflux and does not provide any

25 information about the minimum heat requirements of the column. In a similar way, as in 
1 the case of a thermal engine, the minimum heat consumption can be determined in

2 relation with the hot and cold temperatures to produce a certain work, for a distillation

3 column the minimum heat consumption can be calculated to achieve a certain

4 separation. In this section, the thermal cycle for a distillation column is presented, and

5 the minimum heat calculated.

6 For this purpose, a delimited number of moles circulating inside a distillation column is

7 considered to perform a thermodynamic cycle, as shown in the T-S diagram (Figure 2).

8 Due to the mass transfer, the composition of the delimited number of moles is changing

9 while ascending or descending along the column. This change of composition by itself

10 does not affect the performance of the cycle because the performance is independent of

11 the working fluid composition. A reversible process is assumed; therefore the heat is

12 provided at a small finite temperature difference above the reboiler temperature $\left(T_{r}\right)$ and

13 eliminated at a small finite temperature difference below the condenser temperature

$14\left(\mathrm{~T}_{\mathrm{c}}\right)$. There is an isothermal phase change in the reboiler and condenser (liquid/vapour)

15 (segments 1-2 and 3-4-5-6). The vapour decreases its temperature while ascending

16 (segment 2-3) by exchanging heat with the descending liquid (segment 6-1) whose

17 temperature increases. At any point inside the distillation column, the liquid and vapour

18 in contact are in equilibrium and therefore have the same temperature. Assuming that

19 the column is adiabatic, the heat eliminated by the ascending vapour must be equal to

20 the heat received by the descending liquid. Therefore, at any column height, the sum of

21 the entropy of the liquid and the vapour must be constant along the column. The change

22 of certain amount of entropy in the liquid is compensated by the same amount of

23 entropy in the vapour. According to this, the grey area under the segment 6-1 (area 6-1-

24 5-8-7-6) should be equal to the grey area under the segment 2-3 (area 2-3-10-9-4-2). In

25 the same time, the process reversibility should be assured. The input and output streams 
1 should be at the same specific entropy that the point to or from they are feed or

2 extracted. Hence, the optimal feed stage is the stage with the same specific entropy, as

3 the feed stream.

4 The overall heat provided to the cycle would be the area under 6-1-2-3 (area 6-1-2-3-10-

5 9-8-7-6), but as there is a heat exchange between both grey areas (6-1 and 2-3), then the

6 heat duty provided is the area under the isotherm 1-2 (area 1-2-4-9-8-5-1). The overall

7 heat to be removed from the cycle is the area under the isotherm 3-6 (area 3-4-5-6-7-8-

8 9-10) which should be considered entirely, as there is no regeneration section as for the

9 heat duty. The result is that the area under the isotherm 1-2 (area 1-2-4-9-8-5-1) is equal

10 to the area under the isotherm 3-6 (area 3-4-5-6-7-8-9-10), this implies that the heat

11 provided to the cycle is equal to the heat eliminated from the cycle. Hence, a distillation

12 column has not a net consume of energy, but it creates a decrease of energy quality. The

13 same heat provided to the reboiler is collected in the condenser, but at a lower

14 temperature (usually there is a small difference between these values, equal to the

15 enthalpy variation between input and output streams). Therefore:

$16 Q_{r}=Q_{c}=Q$

17 According to the heat distribution illustrated in Figure 1, the distillation column heat

18 duty can be divided into the duty required to produce the distillate stream, and the duty

19 required to perform the separation.

$20 \quad Q_{r}^{\prime}+Q_{r}^{\prime \prime}=Q_{c}^{\prime}+Q_{c}^{\prime \prime}$

21 The heat eliminated to produce the distillate $\left(Q{ }^{\prime}{ }_{c}\right)$ requires that the same amount that it was provided to the reboiler $\left(\mathrm{Q}^{\prime}{ }_{\mathrm{r}}\right)$.

$23 \quad Q_{r}^{\prime \prime}=Q_{c}^{\prime \prime}=Q^{\prime \prime}=\lambda \cdot D$ 
1 As it is the same amount, the energy required by the vapour, which is collected as

2 distillate, to reach the top of the column is not considered in the following relations,

3 which take into account only the energy of separation.

$4 \quad Q_{r}^{\prime}=Q_{c}^{\prime}=Q^{\prime}$

$5 \quad T_{r} \cdot\left(S_{2}-S_{1}\right)=T_{c} \cdot\left(S_{4}-S_{5}\right)+T_{c} \cdot\left(S_{3}-S_{4}\right)+T_{c} \cdot\left(S_{5}-S_{6}\right)$

6 As $S_{2}-S_{1}=S_{4}-S_{5}$ and $S_{3}-S_{4}=S_{5}-S_{6}$

$7 \quad \frac{T_{r}-T_{c}}{T_{r} \cdot T_{c}}=2 \cdot \frac{S_{5}-S_{6}}{T_{r} \cdot\left(S_{2}-S_{1}\right)}$

$8 \quad$ As $T_{r} \cdot\left(S_{2}-S_{1}\right)=Q_{r}^{\prime}$, then:

$9 \quad T_{c} \cdot 2 \cdot \frac{S_{5}-S_{6}}{Q_{r}^{\prime}}=\frac{T_{r}-T_{c}}{T_{r}}$

10 The thermal efficiency of Carnot cycle is:

$11 \eta=\frac{T_{r}-T_{c}}{T_{r}}$

$12 T_{c} \cdot 2 \cdot\left(S_{5}-S_{6}\right)=Q_{r}^{\prime} \cdot \eta$

13 The distillation column uses the provided heat with the same thermal efficiency defined

14 by a thermal engine. However, instead of using it to produce work, the distillation

15 column uses it to produce a change of entropy, in other words, to produce the

16 separation. The degradation of thermal energy between reboiler and condenser makes

17 possible to lower the entropy of the material, which is the separation of a liquid mixture

18 [49].Then the term $T_{c} \cdot 2 \cdot\left(S_{5}-S_{6}\right)$ should be equal to the difference of entropy

19 between the output streams and the input streams feed to the column at constant

20 temperature $T_{c}$. Therefore, the minimum heat required for a certain separation depends

21 on the increment of entropy of mixing the product streams to obtain the original feed 
1 streams (change of entropy required by the separation) divided by the thermal efficiency

2 of Carnot.

$3 \quad Q_{r}^{\prime}=\frac{T_{c} \cdot \Delta S_{\text {sep }}}{\eta}$

4 For liquid ideal solutions, where the enthalpy of mixing is close to zero, the excess

5 entropy is negligible. The entropy of mixing of ideal liquids can be approximated to the

6 mixing entropy of gases [50], according to the following equation:

$7 \quad \Delta S_{\text {sep }}=R \cdot\left[(D+B) \cdot\left(\sum x_{i}^{\text {feed }} \cdot \ln x_{i}^{\text {feed }}\right)-D \cdot\left(\sum x_{i}^{\text {distil }} \cdot \ln x_{i}^{\text {distil }}\right)-B \cdot\left(\sum x_{i}^{\text {residue }} \cdot \ln x_{i}^{\text {residue }}\right)\right]$

8 Notice that Q' ${ }_{\mathrm{r}}$ represents only the energy to perform the separation. Therefore, the heat

9 required by the distillate to reach the top of the column should be added to obtain the

10 overall minimum reboiler requirements. When two streams of different compositions

11 are mixed, there is entropy of mixing, but sometimes the enthalpy of mixing can be

12 significant enough to be taken into consideration. Therefore the energy provided to the

13 column corresponds to the reboiler duty, adding the enthalpy of mixing as a factor of

14 correction.

$15 Q_{r}^{\prime}+\Delta H_{\text {mixing }}=\frac{T_{c} \cdot \Delta S_{\text {sep }}}{\eta}+\lambda \cdot D$

16 The reboiler duty of a distillation column should be higher than the previously

17 calculated value, due to the irreversibility produced when mixing the column internal

18 flows, and also when mixing the feed streams with the internal flows. The irreversibility

19 produced by the feed streams is obvious in multicomponent systems by the deviation of

20 the column profile around this point.

21 Another assumption in addition to the reversibility of the process is to consider a

22 constant molar overflow along the column. According to this, an estimate of the

23 minimum reflux ratio can be calculated as follows: 
$1 \quad r=\frac{L \cdot \lambda}{D \cdot \lambda+\Delta H_{\text {mixing }}}$

2 where

$3 L \cdot \lambda=\frac{T_{c} \cdot \Delta S_{s e p}}{\eta}$

4 therefore:

$5 \quad r=\frac{T_{c} \cdot \Delta S_{\text {sep }}}{\eta \cdot\left(D \cdot \lambda+\Delta H_{\text {mixing }}\right)}$

7 In this case, the reflux represents the ratio between the energy to perform the separation

8 including the efficiency of Carnot and the energy required to collect the distillate stream

9 at the top of the column.

10

11 3. Validation of the method by rigorous simulation

12

$13 \quad 3.1$ Validation of the minimum Number of Transfer Units

14

15 There are no real stages or integral steps in a packed distillation column, and therefore

16 the NTU are different from the number of theoretical stages proposed by Daniels and

17 Alberty (1975) [51] and calculated discrete liquid vapour equilibrium changes at each

18 stage (it is not a continuous variation). These are only equal when the equilibrium curve

19 is parallel to the operation line, a condition rarely occurring. If the driving force values

20 increase ( $\mathrm{y}_{\mathrm{i}}-\mathrm{X}_{\mathrm{i}}$ in Eq. 3), fewer transfer units than theoretical plates are required; if

21 values of driving force decrease, the reverse is true. Therefore, a condition of equimolar

22 flow rate distribution between distillate and bottom is considered in the illustrative

23 examples used to check the NTU. The number of theoretical stages provided by 
1 rigorous simulation is used together with the infinite reflux condition to cancel the

2 above mentioned deviations. Therefore, the equilibrium and operating line diverge over

3 part of the distillation range and converge over another part providing a total number of

4 transfer units practically equal to the total number of theoretical plates [44].

5 Rigorous simulation using a great reflux ratio is used to validate Eq. 18. A reflux ratio

6 of 1000 considered, for approaching to the assumption of infinite reflux flow rate, and

7 therefore, to obtain the minimum number of stages. The mixtures evaluated (expressed

8 in molar fractions) are shown in Table 1, the calculation basis implemented for all of

9 them is of $100 \mathrm{kmol} / \mathrm{h}$. Feed mixtures considered, allow equimolar sharp split between

10 distillate and bottom and therefore the distillate flow rate is set to $50 \mathrm{kmol} / \mathrm{h}$.

11 The results of rigorous simulation are presented graphically in Figures 3 - 5 illustrating

12 the distillation column composition profiles. The $\mathrm{x}$-axis represents the number of stages

13 required resulted from simulation, while the calculated NTUs with the proposed method

14 are presented on the secondary y-axis. The slope of NTU points with values around 1

15 confirms the equivalence between NTU and minimum number of stages as expected for

16 the proposed conditions.

17

18 The NTU calculated are around $11 \%$ more than the number of stages resulted from

19 rigorous simulation for both binary mixtures studied (case A is shown in Figure 3 and

20 case $\mathrm{C}$ is shown in Figure 4). Since the simulations are performed at infinite reflux,

21 cases B and D are included as a part of the previous figures. In this case, the purity of

22 the distillate and bottom streams was not set as a design specification. Counting the

23 number of stages between any two composition values provides the required minimum

24 number of stages necessary for the separation. 
1 For the binary cases, as the number of stages increases, the purity of the products in

2 distillate and bottoms increases as well. An increase of the number of stages graphically

3 results in a larger flat zone near pure products compositions at both profile ends. For the

4 multicomponent mixture, the simulation results are represented as a residue curve

5 following binary mixtures, where the singular points of the column profile are pure o-

6 cresol and pure p-cresol. An increase of the number of stages graphically results in a

7 larger flat zone near these two pure products in the middle of the profile (Figure 5). The

8 ratio between number of stages resulted from simulation and the NTU calculated with

9 the proposed method changes according to the binary mixture present. At the bottoms of

10 the column, the NTUs are $21 \%$ more than the number of stages and at the top of the

11 column are $7 \%$ less, while in the centre, where the equilibrium curve becomes parallel

12 to the diagonal, are almost identical. Therefore, the number of stages obtained from

13 rigorous simulation and calculated NUTs are in agreement along most of the distillation

14 column profile.

$16 \quad 3.2$ Validation of the minimum reboiler duty and reflux

18 The proposed method (point 2.2) calculates the minimum reflux and the minimum

19 energy requirements using only the thermodynamic information from the input and

20 output streams of the distillation column at the condenser temperature. Therefore, these

21 can be calculated considering a process scheme design opposite to distillation: feed the

22 distillate and bottoms streams to a mixer to obtain as output the column feed

23 composition. For validation of the proposed method, the results obtained by rigorous

24 simulation of a distillation column are compared with the values calculated from the

25 entropy and enthalpy of mixing (Figure 6). These properties of mixing are calculated at 
1 a constant temperature corresponding to the condenser temperature. The enthalpy of

2 mixing is calculated according to the cooling required to bring the resulting mixed

3 stream back to condenser temperature.

4 The mass and energy balances inside the column, taking into account the irreversibility,

5 are calculated by distillation column rigorous simulation with AspenPlus ${ }^{\circledR}$, considering

6 UNIFAC thermodynamic model. The ascending vapour is mixed with the descending

7 liquid and the entrance of feed streams produces irreversibility. To validate the data

8 collected by the simple mixer, a rigorous simulation of a distillation column at 1 bar

9 with a big number of stages (200 stages) with the feed stage in the middle is used. A

10 design specification changes the reflux ratio at the total condenser, for getting the

11 desired purity in the output streams. As the number of stages is big enough, the reflux

12 and reboiler duty should be close to their minimum values. The mixtures evaluated

13 (expressed in molar fractions) and design specifications are shown in Table 1, the

14 calculation basis implemented for all of them is of $100 \mathrm{kmol} / \mathrm{h}$. Feed mixtures

15 considered, allow equimolar sharp split between distillate and bottom, and therefore the

16 distillate flow rate is set to $50 \mathrm{kmol} / \mathrm{h}$.

17 The specific entropy for the input and output streams in the mixing process (Figure 6b)

18 and the heat duty to the cooler for each case (enthalpy of mixing) are presented in Table

19 2. The boiling points of the distillate and residue streams correspond to the temperatures

20 in the reboiler and in the column condenser, being presented in Table 3, together with

21 minimum reboiler duty and minimum reflux, estimated by rigorous simulation. The

22 column efficiency can be calculated using the condenser and reboiler temperatures in

23 the same way as for a thermal engine (Eq. 26); the results are presented in Table 4. The

24 energy loss due to mixing the streams (Figure 6b) is calculated between input and

25 output streams, as product of the specific entropy and flow rates for each stream 
1 multiplied by the condenser temperature (see column $\mathrm{T} \cdot \Delta \mathrm{S}_{\text {sep }}$ in Table 4 ). The

2 reboilerduty required to separate again the mixture (Q') is calculated according to (Eq.

3 28). Moreover, an additional reboiler duty Q' related to the distillate should be taken

4 into account (Eq. 20), according to the scheme in Figure 1, allowing to obtain the

5 overall reboiler duty Q (Table 4). The results of the minimum reboiler duty and

6 minimum reflux estimated by rigorous simulation are compared to their equivalent

7 values calculated by the proposed method (Table 5). The discussion of the results is

8 provided in the following paragraphs.

9

10 In the first case (A), a binary mixture of methanol and ethanol is evaluated (case A

11 Table 1). This is discussed in more detail, according to the proposed method. A stream

12 with $95 \%$ methanol and 5\% ethanol at 1 bar, at its boiling point is mixed with another

13 stream containing 5\% methanol and 95\% ethanol at 1 bar and same temperature. Both

14 streams have same flowrate i.e. $50 \mathrm{kmol} / \mathrm{h}$, (Figure 6b). In this way, both streams are at

15 the same temperature as the column distillate temperature $\left(\mathrm{T}_{\mathrm{c}}=337.8 \mathrm{~K}\right)($ Figure 6a).

16 Due to the enthalpy of mixing, the temperature of the mixed stream increases slightly

17 ( $\mathrm{T}=343.1 \mathrm{~K})$. Therefore the heat exchanger B3 is used to cool this stream back to the

18 temperature of the feed streams. The heat consumed by this cooler corresponds to the

19 enthalpy of mixing $\left(\Delta \mathrm{H}_{\text {mixing }}=4.57 \mathrm{~kW}\right)$.

20 Once mixed, a higher amount of energy is required to separate it again. This energy

21 must come from a distillation column that can be considered as a thermal machine

22 working between a hot and cold source, the reboiler being the hot source and the

23 condenser the cold source. As demonstrated previously, efficiency of Carnot is also

24 applicable to the distillation columns and therefore the required heat for the separation

$25\left(Q^{\prime}=-942.32 \mathrm{~kW}\right)$ represents the energy due to the entropy of mixing $\left(\mathrm{T} \Delta \mathrm{S}_{\mathrm{sep}}=-33.52\right.$ 
$1 \mathrm{~kW})$ divided by the efficiency of the Carnot cycle $(\eta=0.0356)(\mathrm{Eq} .28)$. The entropy of

2 mixing and the efficiency are calculated as follows.

3 The entropy of each stream is calculated as product of its flow rate and specific entropy

4 (Table 2). The difference of entropy between the input and the output streams at

5 temperature $\mathrm{T}_{\mathrm{c}}$ provides the entropy of mixing $\left(-355.3 \mathrm{~kJ} \cdot \mathrm{h}^{-1} \cdot \mathrm{K}^{-1}\right)$. The product between

6 the entropy of mixing and the temperature $T_{c}$ provides the energy loss by the entropy

7 generated: $33.52 \mathrm{~kW}$ (Table 4). The temperature in the reboiler $\left(\mathrm{T}_{\mathrm{r}}\right)$ is $350.26 \mathrm{~K}$ which

8 represents the boiling point of $95 \%$ ethanol stream. The temperature in the condenser

$9 \quad\left(\mathrm{~T}_{\mathrm{c}}\right)$ is of $337.8 \mathrm{~K}$ (Table 3), representing the boiling point of $95 \%$ methanol stream.

10 Therefore, the efficiency calculated from the previous temperature values (Eq. 26) is of

$113.56 \%$ (Table 4).

12 The reboiler duty $(\mathrm{Q}=-1,435.15 \mathrm{~kW})$ is the sum of the energy required by the distillate

13 stream $\left(Q^{\prime \prime}=-492.83 \mathrm{~kW}\right)$ and the energy required to separate the mixture $\left(Q^{\prime}=\right.$ -

$14942.32 \mathrm{~kW}$ ) (Table 4). The enthalpy of mixing is added to the minimum reboiler duty

15 simulated $\left(\mathrm{Q}_{\min }\right)$, but in this case its influence is negligible. By rigorous simulation of a

16 distillation column, the condenser duty resulted is of $1,640.40 \mathrm{~kW}$, only $14 \%$ higher

17 than the one calculated thermodynamically. Using these results and the Eq.(33) to

18 determine the reflux, a calculated reflux of 1.9 is obtained versus a value of 2.3

19 estimated by rigorous simulation (Table 5). Therefore, the values thermodynamically

20 calculated are in very good agreement with the values estimated by rigorous simulation.

22 In case B, the same separation is considered as in case A (methanol and ethanol), but

23 they are separated to a higher purity of $99 \%$ (Table 1). The efficiency obtained is similar

24 to that obtained for case A (3.85\%), but the enthalpy of mixing is not any more

25 negligible (-495.24 $\mathrm{kW}$ ) (Table 2). The minimum thermodynamic reboiler duty is 
1 greater than in case $\mathrm{A}$, as expected $(\mathrm{Q}=-1,594.08 \mathrm{~kW})$, but the simulated condenser

2 duty $\left(\mathrm{Q}_{\min }=-1,779.50 \mathrm{~kW}\right)$ is $61.9 \%$ higher than the one thermodynamically calculated

3 (Table 4). When the enthalpy of mixing is added to the simulated minimum reboiler

4 duty, the difference between them is about $43 \%$. These results show that when the

5 enthalpy of mixing is not negligible, the irreversibility inside the column is higher.

6

7 In case $\mathrm{C}$ separation of binary mixture benzene and toluene is considered to obtain

8 purity of $95 \%$ (Table 1). The enthalpic and entropic contribution to the mixing is similar

9 to the previous $B$ case (Table 2 and 4$)$, e.g. $\Delta \mathrm{S}_{\mathrm{sep}}\left(\mathrm{C}: 455.62 \mathrm{~kJ} \cdot \mathrm{h}^{-1} \cdot \mathrm{K}^{-1}\right.$ and B:451.44

$10 \mathrm{~kJ} \cdot \mathrm{h}^{-1} \cdot \mathrm{K}^{-1}$ ) are almost the same. The higher difference between the condenser and

11 reboiler temperature (for case C: 353.8 - 381.1 K and for case B: 337.4-351.0 K)

12 produces a higher efficiency (7.15\%) and the resulting Q' required for the separation

13 becomes considerable smaller (-622.78 kW) (Table 4). When Q' is compared to the

14 condenser duty value obtained by rigorous simulation of the distillation column $\left(\mathrm{Q}_{\min }=\right.$

$15-932.17 \mathrm{~kW}$ ), the difference is of $48.6 \%$. When the enthalpy of mixing is taken into

16 account this difference becomes $29 \%$. Also the reflux for case $\mathrm{C}$ is smaller than for case

17 B. The thermodynamically calculated reflux is of 1.08 and the estimated reflux value

18 obtained by rigorous simulation is of 1.16 , which is in good agreement. Therefore,

19 higher is the difference between the distillate and bottoms temperatures, the process is

20 more efficient and a lower reflux is required.

22 In case D same binary system as in case $\mathrm{C}$ is considered, but at a higher purity of $99 \%$

23 for the output streams (Table 1) is imposed. The enthalpy of mixing and energy required

24 for the distillate stream are almost similar to case C. But as the purities are higher, the

25 temperatures of distillate and bottom streams differ more, while the efficiency also 
1 increases (7.8\%). Nevertheless, the entropic contribution to the energy of mixing

2 increases at a higher extent resulting in a higher thermodynamic condenser duty (Q') of

$3-726.35 \mathrm{~kW}$ (Table 4), although the efficiency is higher. The condenser duty estimated

4 by simulation is of $-242.75 \mathrm{~kW}$, the difference to the one calculated thermodynamically

5 being around $38.7 \%$ (Table 3 ). When corrected using the enthalpy of mixing, the

6 difference is of $25 \%$. The calculated reflux is of 1.19 and the value estimated by

7 rigorous simulation is of 1.37 , with only $15 \%$ of difference. Therefore, the higher

8 condenser duty and the reflux required to obtain a higher purity is mainly consequence

9 of the higher entropy of mixing. Notice that the minimum condenser duty to separate a

10 binary mixture in pure components is a finite value, and it can be used to calculate the

11 energy requirements of a process under the infinite/infinite assumption.

13 Once verified the obtained results with the estimated values by rigorous simulations for

14 binary mixtures, in case E (Table 1) the results obtained for an equimolar

15 multicomponent mixture of $100 \mathrm{kmol} / \mathrm{h}$ composed of phenol, o-cresol, m-cresol and

16 3,5-xylenol are presented. Phenol and o-cresol are separated in distillate stream with an

17 overall purity of $95 \%$ whereas m-cresol and 3,5-xylenol are separated in bottoms

18 stream, using a distillate flow rate of $50 \mathrm{kmol} / \mathrm{h}$. The enthalpy of vaporization for the

19 distillate stream (Q') is $-655.70 \mathrm{~kW}$, the enthalpy of mixing is $-2.63 \mathrm{~kW}$ and the energy

20 required for separation (Q') is of $-1,071.75 \mathrm{~kW}$ (efficiency of $5.14 \%$ ) resulting in

21 condenser duty of $-1,727.45 \mathrm{~kW}$. The difference between calculated value and the value

22 resulted from rigorous simulation for the condenser duty $(-2,599.91 \mathrm{~kW})$ is of $51 \%$.

23 This difference is quite high compared to the equivalent case A, with a negligible heat

24 of mixing. The irreversibility is caused by the perturbation produced by the feed stream.

25 This is illustrated by column composition profile. The feed position can be easily 
1 identified in Figure 7 due to the deviations and break of the composition column

2 profiles near the feed point.

3

4 In case $\mathrm{F}$, similar multicomponent separation problem to case $\mathrm{E}$ is proposed, but the

5 purity of product streams is imposed to $99 \%$ (Table 1). The entropic contribution to the

6 energy of mixing in this case increases, as expected, to a higher value (-67.40 kW), but

7 the main difference is that the enthalpy of mixing is not any more negligible (-656.27

$8 \mathrm{~kW})$. The calculated condenser duty (Q) is $-1,907.66 \mathrm{~kW}$ and the estimated one by

9 rigorous simulation $\left(\mathrm{Q}_{\min }\right)$ is $-2,942.79 \mathrm{~kW}$ which becomes $-3,599.40 \mathrm{~kW}$ (Table 5)

10 when taking into account the enthalpy of mixing. In this case, the difference is $89 \%$

11 compared to the thermodynamically calculated one. The reason for the higher

12 discrepancy for multicomponent mixtures can be explained by the composition profiles

13 which present a remarkable break of the tendency for some of the components at the

14 feed plate. This leads to a high degree of irreversibility. Furthermore, the irreversibility

15 produced by the enthalpy of mixing is sharpened by the irreversibility produced at the

16 feed plate. A continuous computation of the packed columns would provide values

17 closer to the calculated ones, assuming a reversible separation instead of the rigorous

18 model implemented in the simulator which takes into account discrete stages.

\section{TAME synthesis as illustrative example for the proposed method}

22 The previously presented problems are easily studied directly by rigorous simulation, but there are more complex processes not so easy to analyse. For instance, the synthesis of TAME (tert-amyl-methyl-ether), an important gasoline additive, can be performed using the technology of catalytic distillation (from methanol and isoamylenes) in a 
1 hybrid reactive distillation column with the non-reactive section in the bottom. The

2 feasibility and the influence of several design parameters on the number of stages and

3 energy consumption of such a complex process is not an easy task to be analysedby

4 rigorous simulation. The convergence of the simulation environment requires a long

5 time of trials and the difficulty to reach a converged flowsheet is not always a sign of

6 non-feasibility of the configuration considered. To determine all the feasible

7 combinations of parameters influencing the system analysedis not always straight-

8 forward. Therefore, the proposed method simplifies the model at the extreme conditions

9 to avoid the convergence problems and provide a fast insight of the problem behaviour.

10 This behaviouris reflected in two kinds of complementary maps: a map illustrating

11 feasibility and minimum number of stages and a map showing the distillation column

12 thermal efficiency. The first map is based on the assumption of infinite reflux flow rate

13 and the difficulty of the separation is reflected in the NTUs required according to the

14 Eq.(18). The second map is based on the thermal efficiency that defines the minimum

15 energy requirements of the distillation column and the minimum reflux. The thermal

16 efficiency of the distillation column depends only on the temperatures of distillate and

17 bottom streams. The aspect of both graphics is similar to a topographic map. The main

18 coincidence between them is that the maximum and minimum temperatures coincide

19 also with singular points (pure components or azeotropes) at which the difficulty of

20 separation is maximum as well. As differences, the temperature map topology does not

21 depend on the retention time inside the reactive distillation column, while the NTUs

22 map topology strongly depends on the retention time. Pressure influences both types of

23 map topology, but at different extent. These maps are discussed for this illustrative

24 example in more detail in the following paragraphs. 
1 Figure 8 illustrates the maps at 4 bar. The NUTs map is composed of a set of curves

2 obtained when applying Eq.(18). Any feasible separation composition can be placed on

3 a common residue curve and the section of curve between them corresponds to the

4 distillation column composition profiles assuming a packed column operated at infinite

5 reflux flow rate. The minimum NTUs for the required separation are mathematically

6 obtained integrating Eq.(18). Graphically, the minimum NTUs can be directly obtained

7 when counting the number of circles in the section of curve corresponding to the

8 column profile. The NUTs map for TAME synthesis is divided in two distillation

9 regions with a common unstable node (isoamylenes/methanol azeotrope). Most of the

10 feasible column profiles depart from this azeotrope and converge to pure TAME vertex,

11 while some other column profiles converge to pure methanol. The optimum profile

12 corresponds to minimum NTUs required for a separation, fulfilling certain restrictions

13 to bottoms and distillate compositions. It is obtained when the profile crosses regions

14 where the separation is fastest (maximum difference between the $\mathrm{y}_{\mathrm{i}} \mathrm{term}$ and the rest in

15 Eq. 18) and the way is shortest (the overall NTUs resulted from integration).

16 Comparing both maps (Figure 8), the maximum temperatures correspond to stable

17 nodes, e.g. pure TAME, and the minimum temperature corresponds to the unstable

18 node, i.e. methanol/isoamyleneazeotrope. The column efficiency can be determined

19 easily from Eq.(26) as it only depends on temperature. Therefore, when the distillation

20 column is operated in the distillation region corresponding to methanol stable node, the

21 NTUs are small but the thermal efficiency is low. On the other hand, the operation in

22 the distillation region corresponding to TAME stable node requires more NTUs, but the

23 thermal efficiency is higher. The presence of the reaction term does not change the

24 column efficiency as the boiling points at each composition are the same. The enthalpy

25 of the reaction must be taken into account when the minimum reboiler duty is 
1 calculated. However, the presence of reaction influences the topology of the NTUs map,

2 changing the position of the nodes and saddles and affecting the difficulty of separation

3 (Figure 9).

4 The temperatures map and the representation of NTUs on residue curve maps provide

5 an useful tool and a valuable additional information to propose more energy efficient

6 process schemes and designs.

7

8 5. Summary of the proposed method

9

10 The feasibility of a distillation process requires the fulfilment of the mass balances and

11 the existence of a column profile between the distillate and bottoms composition. The

12 existence of the column profile can be checked at infinite reflux using the following

13 expression (Eq. 16) for packed columns:

$14 \frac{d x_{i}}{d N T U}=\left(y_{i}-\frac{x_{i}+\tau \cdot \sum_{j=1}^{M} v_{i, j} \cdot r_{j}}{1+\tau \cdot \sum_{j=1}^{M} v_{T, j} \cdot r_{j}}\right) \cdot\left(\frac{d \overline{y_{i}}}{d x_{i}}\right)^{-1}$

15 This expression is implemented in most of the commercial simulators but only for non-

16 reactive mixtures and does not indicate the NTU. The NTU is an important parameter as

17 provides an insight of the capital costs associated to the separation. In a more

18 approximated manner, the capital costs associated can be considered related to the

19 residue curve or profile length. Eq. (16) is a general expression taking into account the

20 reaction kinetics, but it can be simplified for non-reactive systems to Eq. (6):

$21 \frac{d x_{i}}{d N T U}=x_{i}-y_{i}$ 
1 The last expressions are the basis for the infinite reflux assumption analysis models, e.g.

2 infinite/infinite analysis, and therefore the output streams compositions and flow rate

3 can be determined. A separation is feasible only if the reflux is higher than its minimum

4 value, therefore the minimum reflux is valuable information that in turn is related to the

5 operational costs. The optimum reflux is usually calculated with rules of thumb that

6 relates it with its minimum value. The present paper presents an original way to

7 calculate it from thermodynamic assumptions (Eq. 33):

$8 \quad r=\frac{T_{c} \cdot \Delta S_{\text {sep }}}{\eta \cdot\left(D \cdot \lambda+\Delta H_{\text {mixing }}\right)}$

9 where

$10 \eta=\frac{T_{r}-T_{c}}{T_{r}}$

$11 \Delta S_{\text {sep }}=R \cdot\left[(D+B) \cdot\left(\sum x_{i}^{\text {feed }} \cdot \ln x_{i}^{\text {feed }}\right)-D \cdot\left(\sum x_{i}^{\text {distil }} \cdot \ln x_{i}^{\text {distil }}\right)-B \cdot\left(\sum x_{i}^{\text {residue }} \cdot \ln x_{i}^{\text {residue }}\right)\right]$

12 The results of this method (minimum NTU and reflux) can be used as initialization

13 values for iterative more rigorous methods.

14 6. Conclusions

15 This paper proposes a new expression to model the compositions profile of a packed

16 distillation column operated at infinite reflux flow rate. The results can be used to

17 determine the minimum Number of Transfer Units for a given separation. NUT is useful

18 to evaluate de difficulty of the separation, complementing the information from residue

19 curve maps for the feasibility of the separation. An original treatment is proposed to

20 evaluate feasibility/difficulty of separation for reactive distillation. On the other hand, it

21 is proposed an original method to calculate the minimum reboiler duty, based on the

22 thermodynamic efficiency of a distillation column, and the change of entropy between

23 the input and output streams. Higher the difference between the distillate and bottoms

24 compositions, more efficient is the distillation column. The separation leading to 
1 streams of higher purity is associated to a higher efficiency. The entropic contribution to

2 the energy of mixing, increases the energy requirements at a higher extent than the

3 savings due to the increase of efficiency producing higher reboiler duty requirements.

4 The minimum reboiler duty to separate a binary mixture in pure components is a finite

5 value, but the number of transfer units to separate in pure components is considered

6 infinite. Therefore the method can be applied in combination with the infinite/infinite

7 analysis.

8 When the heat of mixing is negligible, the results are in very good agreement with the

9 values estimated by rigorous simulation. Otherwise, a higher difference is observed

10 between the minimum reboiler duty thermodynamically estimated, and the one

11 calculated by rigorous simulation. This is caused by irreversibility produced due to

12 mixing inside the distillation column between liquid and vapour flowing in opposite

13 directions. The irreversibility is sharpened in multicomponent mixtures due to the feed

14 stream that produces a clear perturbation of the composition profiles for several

15 compounds. Due to the irreversibility, the estimated minimum reboiler duty by rigorous

16 simulation can be several times bigger than the minimum thermodynamically calculated

17 value.

19 Acknowledgements The authors would like to thank the financial support of POSCCE

20 project ID 652 (Structural Funds for Development and Cohesion) and the project

21 CTQ2009-11465 (Ministry of Science and Innovation - Spanish Government) who

22 provided the opportunity to complete this research.

\section{References}


1 [1] F.B. Petlyuk, V.S. Avetyan, Investigation of the rectification of three-component

2 mixtures with infinite reflux, Theor.Found.Chem.Eng. 5(1971) 499-507.

3

4 [2] J. Bonet, R. Thery, X.-M. Meyer, M. Meyer, J.-M.Reneaume, M.-I. Galan, J. Costa,

5 Infinite/Infinite Analysis as a Tool for an Early Oriented Synthesis of a Reactive

6 Pressure Swing Process, Computers \& Chemical Engineering 31(5-6) (2007) 487-495.

7

8 [3] A.E. Pleşu, J. Bonet, V. Pleşu, G. Bozga, M.-I.Galan, Residue Curves Map Analysis

9 for Tert-Amyl Methyl Ether Synthesis by Reactive Distillation in Kinetically Controlled

10 Conditions with Energy-Saving Evaluation, Energy 33 (10) (2008) 1572-1589.

11

12 [4] O. Ryll, S. Blagov, H. Hasse, $\infty / \infty$-Analysis of Homogeneous Distillation Processes,

13 Chemical Engineering Science 84 (2012) 315-332.

14

15 [5] A.E. Bonet-Ruiz, J. Bonet Ruiz, V. Pleşu, G. Bozga, J. LlorensLlacuna, J. Costa

16 Lopez, New Contributions to Modelling and Simulation of TAME Synthesis by

17 Catalytic Distillation, Chemical Engineering Transactions 18 (2009) 959-964.

18

19 [6] A.E. Bonet-Ruiz, J. Bonet, G. Bozga, J. LlorensLlacuna, V. Pleşu, Number of

20 Transfer Units Information on Residue Curve Maps, Chemical Engineering

21 Transactions 21 (2010) 1417-1422.

22

23 [7] A.E. Bonet Ruiz, Modelling and Simulation of Continuous Catalytic Distillation

24 Processes, PhD Thesis, Bucharest, Romania, 2012, romdoc.upb.ro/record/623, accessed $2518^{\text {th }}$ of November 2012. 
2 [8] L. Laroche, N. Bekiaris, H.W. Andersen, M. Morari, Homogeneous Azeotropic

3 Distillation: Separability and Flowsheet Synthesis, Ind. Eng. Chem. Res. 31 (1992)

$4 \quad 2190-2209$.

5

6 [9] D.VanDongen, M. Doherty, Design and Synthesis of Homogeneous Azeotropic

7 Distillations 1: Problem Formulation for a Single Column, I\&EC Fundamentals 24(4)

$8 \quad(1985) 454-463$.

9

10 [10] A.E. Bonet-Ruiz, J. Bonet Ruiz, G. Bozga, J. LlorensLlacuna, V. Pleşu, A.Tuluc,

11 G. Bumbac, C. Muscalu, Modelling and Experiments for Application of Catalytic

12 Distillation to TAME Synthesis, Chemical Engineering Transactions 29 (2012) 1501 131507.

14

15 [11] A.E. Bonet-Ruiz, J. Bonet, V. Pleşu, G. Bozga, Environmental performance

16 assessment for reactive distillation processes, Resources Conservation and Recycling

$1754(5)(2010) 315-325$.

18

19 [12] Z. Varga, I. Rabi, K. KubovicsStocz, Process simulation for improve energy

20 efficiency, maximize asset utilization and increase in feed flexibility in a crude oil

21 refinery, Chemical Engineering Transactions 21 (2010) 1453-1458.

22

23 [13] R. Smith, M. Jobson, L. Chen, S. Farrokhpanah, Heat integrated distillation system

24 design, Chemical Engineering Transactions, 21 (2010) 19-24. 
1 [14] L. Sikos, J. Klemeš, Reliability, availability and maintenance optimisation of heat

2 exchanger networks, Applied Thermal Engineering 30 (2010) 63-69.

3

4 [15] P. Glavič, Thirty Years of International Symposia on Process Systems Engineering,

5 Current Opinion in Chemical Engineering, 1 (2012) 421-429.

6

7 [16] J. Bonet Ruiz, A.E. Bonet-Ruiz, V.-C.Radu, J. LlorensLlacuna, J. Costa Lopez, A

8 simplified cost function for distillation systems evaluation, Chemical Engineering

9 Transactions 21 (2010) 1405-1410.

10

11 [17] K. Hirata, Heat integration of distillation column, Chemical Engineering

12 Transactions 18 (2009) 39-44.

13

14 [18] Y. Kansha, A. Kishimoto, A. Tsutsumi, A new design methodology for heat

15 integrated distillation column based on self-heat recuperation, Chemical Engineering

16 Transactions 21 (2010) 43-48.

17

18 [19]Y. Kansha, N. Tsuru, C. Fushimi, A. Tsutsumi, A new design methodology of

19 azeotropic distillation processes based on self-heat recuperation, Chemical Engineering

20 Transactions 18 (2009) 51-56.

21

22 [20] L. Szabó, M.G. Balaton, S. Németh, F. Szeifert, Modelling of divided wall column,

23 Chemical Engineering Transactions 21 (2010) 67-72. 
1 [21] D.F. Mendoza, C.A.M. Riascos, Entropy minimization in design of extractive

2 distillation system with internal heat exchangers, Chemical Engineering Transactions 25

3 (2011) 405-410.

4

5 [22] F.O. Barroso-Muñoz, M.D. López-Ramírez J.G. Díaz-Muñoz, S. Hernández, J.G.

6 Segovia-Hernández, H. Hernández-Escoto, R.H.C. Torres, Thermodynamic analysis and

7 hydrodynamic behavior of a reactive dividing wall distillation column, Chemical

$8 \quad$ Engineering Transactions 17 (2009) 1263-1268.

9

10 [23] R. Taylor, R. Krishna, Multicomponent Mass Transfer, John Wiley and Sons Inc., 11 New York, USA, 1993.

12

13 [24] R. Thery, X.M. Meyer, X. Joulia, M. Meyer, Preliminary design of reactive

14 distillation columns, Chemical Engineering Research and Design 83 (2005) 379-400.

15

16 [25] R. Brunet, D. Cortes, G. Guillen-Gosalbez, L. Jimenez, D. Boer, Minimization of

17 the LCA impactof thermodynamic cycles using a combined simulation-optimization

18 approach, Applied Thermal Engineering 48 (2012) 367-377.

19

20 [26] E.W. Zavaleta-Aguilar, J.R. Simoes-Moreina, Thermal design of a tray-type

21 distillation column of an ammonia/water absorption, Applied Thermal Engineering 41

22 (2012) 52-60. 
1 [27] S. Levy, D. Van Dongen, M.F. Doherty, Design and synthesis of homogeneous

2 azeotropic distillations: 2. Minimum reflux calculations for nonideal and azeotropic

3 columns, Industrial Engineering Chemical Fundam. 24 (1985) 463-474.

4

5 [28] L. Zhang, A.A. Linninger, Towards computer-aided separation synthesis, AIChE 6 Journal 52 (2006) 1392-1409.

7

8 [29] A. Lucia, A. Amale, R. Taylor, Distillation pinch points and more, Computers \& 9 Chemical Engineering 32 (2008) 1342-1364.

10

11 [30] A.S. Amale, A. Lucia, Non-pinched, minimum energy distillation designs,

12 Chemical Engineering Research and Design 86 (2008) 892-903.

13

14 [31] N. Zhang, R. Smith, I. Bulatov, J.J. Klemes, Sustaining high energy efficiency in 15 existing processes with advanced process integration technology, Applied Energy 101 16 (2013) 26-32.

17

18 [32] M.I. Balashov, L.A. Serafimov, The static analysis of continuous combined

19 reactive distillation processes, Theoretical foundations of chemical engineering14 (1980)

$20 \quad 803-808$.

21

22 [32] V. Julka, M.F. Doherty, Geometric behavior and minimum flows for nonideal 23 multicomponent distillation, Chemical Engineering Science 45 (1990) 1801-1822. 
1 [33] J. Kohler, P. Aguirre, E. Blass, Minimum reflux calculations for nonideal mixtures

2 using the reversible distillation model, Chemical Engineering Science 46 (1991) 300733021.

4

5 [34] P. Pollmann, S.B. Glanz, E. Blass, Calculating minimum reflux of nonideal

6 multicomponent distillation using Eigenvalue Theory, Comput.Chemical Engineering

7 18(Supplement) (1994) S49-S52.

8

9 [35] A. Harwardt, S. Kossack, W. Marquart, Optimal column sequencing for

10 multicomponent mixtures, In: B. Braunschwig, X. Joulia (Eds.) Proceedings for the

11 European Symposium on Computer Aided Process Engineering - ESCAPE 18,

12 Elsevier, Amsterdam, 2008, pp. 91-96.

13

14 [36] J. Bausa, R. von Wartzdorf, W. Marquardt, Shortcut methods for

15 nonidealmulticomponent distillation: 1. Simple columns, AIChE J. 44 (1998) 2181-

162198.

17

18 [37] K. Kraemer, A. Harwardt, W. Marquardt, A novel shortcut method for the design

19 of heteroazeotropic distillation of multicomponent mixtures. In: M. El-Halwagi, A.A.

20 Linninger (Eds.) Proceedings of the Seventh International Conference on the

21 Foundations of Computer-Aided Process Design - FOCAPD, CRC Press, New York, 22 USA, 2009, pp. 1035-1052. 
1 [38] F.B. Petlyuk, Distillation theory and its application to optimal design of separation,

2 Cambridge Series in Chemical Engineering, Cambridge University Press, Cambridge, 32004.

4

5 [39] K. Kraemer, A. Harwardt, M. Skiborowski, S. Mitra, W. Marquardt, Shortcut-

6 based design of multicomponent heteroazeotropic distillation, Chemical Engineering

$7 \quad$ Research and Design 8 (2011) 1168-1189.

8

9

10 [40] N. Bekiaris, G. Meski, C. Radu, M. Morari, Multiple Steady States in

11 Homogeneous Azeotropic Distillation, I\&EC Research 32 (1993) 2023 - 2038.

12

13 [41] E.R. Gilliland, Multicomponent rectification. Estimation of the Number of

14 Theoretical Plates as a Function of the reflux ratio, Industrial and Engineering

15 Chemistry 32 (1940) 1220-1223.

16

17 [42] A. Underwood, Fractional distillation of multi-component mixtures, Chemical

18 Engineering Progress 44 (1948) 603-614.

19

20 [43] M.R. Fenske, Fractionation of Straight-run Pennsylvania Gasoline, Industrial

21 Engineering Chemistry 24 (5) (1932) 482-485.

22

23 [44] T. H. Chilton, A. P. Colburn, Distillation and absorption in packed columns. A

24 convenient design and correlation method, Industrial and Engineering Chemistry 27

25 (1935) 255-260. 
2 [45] J. Ulrich, M. Morari, Operation of homogeneous azeotropic distillation column

3 sequences, Ind. Eng. Chem. Res. 42 (20) (2003) $4512-4534$.

4

5 [46] P. Saneipoor, I. Dincer, G.F. Naterer, Thermodynamic analysis of a new Marnoch

6 Heat Engine, Applied Thermal Engineering (2013) DOI:

7 dx.doi.org/10.1016/j.applthermaleng.2012.12.006.

8

9 [47] S. Carnot, Réflexionssur la puissance motrice du feu : et sur les machines propres à

10 développercette puissance, Lib. scientifique et technique A. Blanchard, Nouvelle éd., 11 Paris, 1953.

12

13 [48] T. Benali, D. Tondeur, J.N. Jaubert, An improved crude oil atmospheric distillation 14 process for energy integration: Part I: Energy and exergy analyses of the process when a 15 flash is installed in the preheating train, Applied Thermal Engineering 32 (2012) 12516131.

17

18 [49] M. Haragovics, P. Mizsey, Ranking of rectification structures separating

19 quaternary mixtures with exergy analysis, PeriodicaPolytechnica: Chemical

20 Engineering 56 (2012) 31-35.

21

22 [50] F. Daniels, R.A. Alberty, Physical Chemistry, fourth ed., Wiley, New York, USA, 23 1975. 
$1 \quad$ [52] W.A. Peters, The Efficiency and Capacity of Fractionating Columns, Industrial

2 Engineering Chemistry 14 (1922) 476-479.

3

4

5

6 


\section{$1 \quad$ List of Tables}

2

3 Table 1. Case studies

4 Table 2. Results of rigorous simulation for mixing (Figure 7b)

5 Table 3. Results of rigorous simulation for distillation (Figure 7a)

6 Table 4. Results for minimum heat duty calculated

7 Table 5. Method validation results 
Table 1. Case studies

\begin{tabular}{cccc}
\hline Case & Compounds & $\begin{array}{c}\text { Feed composition } \\
\text { (mole fraction) }\end{array}$ & $\begin{array}{c}\text { Design specification }- \\
\text { distillate stream } \\
\text { (mole fraction) }\end{array}$ \\
\hline A & Methanol - Ethanol & $0.5-0.5$ & 0.95 methanol \\
B & Methanol - Ethanol & $0.5-0.5$ & 0.99 methanol \\
C & Benzene - Toluene & $0.5-0.5$ & 0.95 benzene \\
D & Benzene - Toluene & $0.5-0.5$ & 0.99 benzene \\
E & Phenol & 0.25 & 0.95 phenol + o-cresol \\
& o-cresol & 0.25 & \\
& m-cresol & 0.25 & \\
F & 3,5-xylenol & 0.25 & \\
& Phenol & 0.25 & \\
& o-cresol & 0.25 & \\
& m-cresol & 0.25 & \\
& 3,5-xylenol & 0.25 & \\
\hline
\end{tabular}

2 
1 Table 2. Results of rigorous simulation for mixing (Figure 7b)

\begin{tabular}{ccccc}
\hline Case & $\begin{array}{c}\mathrm{S}_{\text {feed }} \\
(\mathrm{J} / \mathrm{mol} \cdot \mathrm{K})\end{array}$ & $\begin{array}{c}\mathrm{S}_{\text {dist }} \\
(\mathrm{J} / \mathrm{mol} \cdot \mathrm{K})\end{array}$ & $\begin{array}{c}\mathrm{S}_{\text {residue }} \\
(\mathrm{J} / \mathrm{mol} \cdot \mathrm{K})\end{array}$ & $\begin{array}{c}\Delta \mathrm{H}_{\text {mixing }} \\
(\mathrm{kW})\end{array}$ \\
\hline $\mathrm{A}$ & -273.58 & -273.29 & -322.82 & -4.57 \\
$\mathrm{~B}$ & -273.75 & -228.35 & -328.17 & -495.24 \\
$\mathrm{C}$ & -264.05 & -272.16 & -306.81 & -426.44 \\
$\mathrm{D}$ & -264.47 & -228.60 & -311.87 & -422.99 \\
$\mathrm{E}$ & -337.45 & -297.74 & -385.52 & -2.63 \\
$\mathrm{~F}$ & -337.74 & -298.95 & -387.19 & -656.28 \\
\hline
\end{tabular}

2 
1 Table 3. Results of rigorous simulation for distillation (Figure 7a)

\begin{tabular}{ccccc}
\hline Case & $\begin{array}{c}\mathrm{T}_{\mathrm{r}} \\
(\mathrm{K})\end{array}$ & $\begin{array}{c}\mathrm{T}_{\mathrm{c}} \\
(\mathrm{K})\end{array}$ & $\begin{array}{c}\mathrm{Q}_{\min } \\
(\mathrm{kW})\end{array}$ & $\mathrm{r}_{\min }$ \\
\hline $\mathrm{A}$ & 350.26 & 337.80 & $-1,635.82$ & 2.32 \\
$\mathrm{~B}$ & 350.95 & 337.44 & $-1,779.50$ & 2.64 \\
$\mathrm{C}$ & 381.11 & 353.85 & -932.17 & 1.16 \\
$\mathrm{D}$ & 382.91 & 353.05 & $-1,014.70$ & 1.37 \\
$\mathrm{E}$ & 482.62 & 457.81 & $-2,597.27$ & 2.96 \\
$\mathrm{~F}$ & 483.23 & 457.26 & $-2,942.79$ & 3.50 \\
\hline
\end{tabular}

2 
1 Table 4.Results for minimum heat duty calculated

\begin{tabular}{cccccc}
\hline Case & $\begin{array}{c}\mathrm{T} \cdot \Delta \mathrm{S}_{\text {sep }} \\
(\mathrm{kW})\end{array}$ & $\begin{array}{c}\eta \\
(\%)\end{array}$ & $\begin{array}{c}\mathrm{Q}^{\prime} \\
(\mathrm{kW})\end{array}$ & $\begin{array}{c}\mathrm{Q} \% \\
(\mathrm{~kW})\end{array}$ & $\begin{array}{c}\mathrm{Q} \\
(\mathrm{kW})\end{array}$ \\
\hline $\mathrm{A}$ & -33.52 & 3.56 & -942.32 & -492.83 & $-1,435.15$ \\
$\mathrm{~B}$ & -42.56 & 3.85 & $-1,105.25$ & -488.83 & $-1,594.08$ \\
$\mathrm{C}$ & -44.54 & 7.15 & -622.78 & -430.94 & $-1,053.72$ \\
$\mathrm{D}$ & -56.64 & 7.80 & -726.35 & -428.16 & $-1,154.50$ \\
$\mathrm{E}$ & -55.09 & 5.14 & $-1,071.75$ & -655.70 & $-1,727.46$ \\
$\mathrm{~F}$ & -67.40 & 5.37 & $-1,254.42$ & -653.24 & $-1,907.66$ \\
\hline
\end{tabular}

2 
1 Table 5. Method validation results

\begin{tabular}{ccccccc}
\hline Case & $\begin{array}{c}\mathrm{Q} \\
(\mathrm{kW})\end{array}$ & $\begin{array}{c}\mathrm{Q}_{\min }+\Delta \mathrm{H}_{\text {mixing }} \\
(\mathrm{kW})\end{array}$ & $\begin{array}{c}\text { Difference } \\
(\%)\end{array}$ & $\mathrm{r}$ & $\mathrm{r}_{\min }$ & $\begin{array}{c}\text { Difference } \\
(\%)\end{array}$ \\
\hline $\mathrm{A}$ & $-1,435.15$ & $-1,640.40$ & 14 & 1.89 & 2.32 & 22 \\
$\mathrm{~B}$ & $-1,594.08$ & $-2,274.73$ & 43 & 1.81 & 2.64 & 45 \\
$\mathrm{C}$ & $-1,053.72$ & $-1,358.60$ & 29 & 1.08 & 1.16 & 7 \\
$\mathrm{D}$ & $-1,154.50$ & $-1,437.69$ & 25 & 1.19 & 1.37 & 15 \\
$\mathrm{E}$ & $-1,727.46$ & $-2,599.91$ & 51 & 2.87 & 2.96 & 3 \\
$\mathrm{~F}$ & $-1,907.66$ & $-3,599.07$ & 89 & 2.25 & 3.50 & 56 \\
\hline
\end{tabular}

2 


\section{$1 \quad$ List of Figures}

2

3 Figure 1.Heat distribution in the distillation column

4 Figure 2. Thermal cycle for a distillation column

5 Figure 3.NTU validation for an equimolar mixture methanol/ethanol.

6 Figure 4.NTU validation for an equimolar mixture benzene/toluene.

7 Figure 5. NTU validation for an equimolar multicomponent mixture phenol, o-crezole, 8 p-crezole and 3,5-xylenol.

9 Figure 6. Process scheme considered for rigorous simulation

10 Figure 7. Composition column profile deviation near feed stage

11 Figure 8. Temperature and NUTs maps for ternary mixture

12 TAME/methanol/isoamylene at 4 bar.

13 Figure 9. Influence of the reaction term (residence time of $0.01 \mathrm{~s}$ ) on the NUTs maps 14 for ternary mixture TAME/methanol/isoamylene at 4 bar. 